\title{
EVALUATION OF AUTOGENOUS FRESH DEMINERALIZED TOOTH GRAFT PREPARED AT CHAIRSIDE FOR DENTAL IMPLANT (CLINICAL AND HISTOLOGICAL STUDY)
}

\author{
Marwan M. El-Said $B D S^{l}$, Ahmed A. Sharara $P h D^{2}$, Lydia F. Melek $P h D^{3}$,
}

Nesma M. Khalil $P h D^{4}$

\begin{abstract}
INTRODUCTION: Although, the chemical composition of dentin is similar to bone, extracted teeth are still considered a clinical waste and therefore being discarded. With successful extraction of growth factors and bone morphogenic proteins (BMPs) from mammalian teeth, many researchers have supported development of a bone substitute using tooth-derived substances.

OBJECTIVES: To evaluate clinical, radiological and histological efficiency of autogenous fresh demineralized tooth (AFDT) graft prepared at the chairside for alveolar bone grafting in fresh extracted sockets for dental implant surgery

MATERIALS AND METHODS: Ten patients requiring tooth extraction and alveolar bone regeneration for dental implant placement were included in the study. Within 45 minutes the extracted teeth were mechanicaly prepared, grinded, sieved, defatted, demineralized and sterilized. In the same setting, the graft material was used to reconstruct defects at the extraction. After 3 months of uninterrupted healing at time of implant placement bone samples were collected for histological analysis. CBCT were taken preoperative, 3 months after grafting and 3 and 6 months after implant placement.

RESULTS: Histologically the osteoconductive, Osteoinductive and Biodegradation of (AFDT) graft was evident. Clinically $100 \%$ success rate of implants was achieved, with no adverse tissue reaction. CBCT have shown increase of bone density at the graft site and stability of marginal bone level around implants.

CONCLUSIONS: (AFDT) graft should be considered as an option given its autogenous origin and favorable clinical, radiographical and histological outcomes when teeth extraction is necessary.

KEY WORDS: Implants, Autogenous, demineralized tooth graft

1- Post-Graduate Researcher at Oral and Maxillofacial Surgery Department, Faculty of Dentistry, Alexandria University, Alexandria, Egypt.

2- Professor of Oral and Maxillofacial Surgery Faculty of Dentistry, Alexandria University, Alexandria, Egypt.

3- Lecturer at Oral and Maxillofacial Surgery Department, Faculty of Dentistry, Alexandria University, Alexandria, Egypt.

4- Lecturer at Oral Biology Department, Faculty of Dentistry, Alexandria University, Alexandria, Egypt.
\end{abstract}

\section{INTRODUCTION}

Among the highly organized tissue within the human body, jaw bone has the unique regenerative potential to rebuild its original structure and its mechanical properties following the development of a bone defect or fracture. But this regenerative capacity has its limits and may even fail if certain conditions are not fulfilled (1).

Tooth extraction whether due to caries, trauma or advanced periodontal disease causes commonly the alveolar ridge to decrease in volume, including reduced height and width and a change in morphology (2).

The width of the alveolar ridge was found to be reduced by $50 \%$ during the first 12 months after tooth extraction (about 5 to $7 \mathrm{~mm}$ ), and two thirds of this bone loss occurs in the first three months after tooth extraction, suggesting that most of the dimensional alteration of the alveolar ridge takes place within the first 3 months of healing with a corresponding vertical bone loss of 0.9 to $3.25 \mathrm{~mm}(3,4)$.

According to bone healing mechanism, bone graft materials can be categorized into materials that induce osteogenesis, osteoinduction, and osteoconduction (5).

Among the many different types of bone graft materials, autogenous bone is the most ideal since it is capable of osteogenesis, osteoinduction, and osteoconduction (5).

Its advantage is the rapid healing time without immune rejection. As its biggest shortcomings, however, the harvest amount is limited, bone resorption after graft is unavoidable, and second defect is generated in the donor area (5).

Therefore, to overcome such shortcomings, allogenic, xenogeneic, and alloplastic graft materials have been used as alternatives, but they have a number of drawbacks compared with autogenous grafts, such as decreased function, the potential risk of infectious disease, an unsatisfactory resorption pattern, a prolonged healing time, and high cost (6).

An ideal bone graft material should stabilize the blood clot, provide a biomechanical scaffold for cell migration, proliferation, and differentiation, contain functional proteins and peptides, such as growth factors, and exhibit appropriate resorption and remodeling during new bone formation (6).

Materials based on collagen, particularly type I collagen have attracted attention because of their ability to improve the cellular responses of osteogenic lineages, thus ensuring better bone regeneration (6).

Many researchers have examined tooth dentin as a potential carrier for human proteins and as grafting material because its biological composition is very similar to that of alveolar bone $(6,7)$.

In dentin, the inorganic content is $70 \sim 75 \%$, whereas the organic content is about $20 \%$. In alveolar bone, the inorganic content is $65 \%$, and the organic content is $25 \%$. At least $90 \%$ of organic content of dentin is type I collagen, which plays an important role in bone formation and mineralization $(8,9)$. 
Both tooth and alveolar bone are derived from neural crest cells and are made up of the same Type I collagen. Dentin also contains bone morphogenetic proteins (BMP) which promote the differentiation of mesenchymal stem cells into chondrocytes and consequently enhance bone formation $(6,7)$.

Several clinical applications of autogenous demineralized tooth graft were established by the work of Kim, et al in extraction socket preservation and guided bone regeneration (5).

Also efficacy of autogenous demineralized tooth graft in maxillary sinus was demonstrated by retrospective study on sinus bone grafting by Jeong, et al (10), and a study to evaluate histomorphometrically and compare the efficiency of various bone graft materials and autogenous tooth bone graft material used in the sinus bone graft procedure performed by Lee, et al (11).

The aim of the study was to evaluate clinical, radiological and histological efficiency of autogenous fresh demineralized tooth (AFDT) graft prepared at the chairside for alveolar bone grafting in fresh extracted sockets for dental implant surgery.

\section{MATERIALS AND METHODS Patients' selection}

Ten patients in need for tooth extraction of maxillary anterior or premolar teeth were selected from those attending Oral and Maxillofacial Surgery Department, Faculty of Dentistry, Alexandria University.

\section{Inclusion criteria}

Nonsmoker patients in need for extraction of maxillary anterior or premolar teeth aging between 20-50 years old, with good oral hygiene.

\section{Exclusion criteria}

Patients with active infection at extraction site, systemic disorders contraindicating surgery, undergoing chemotherapy or radiotherapy, bone disorders and alcohol or drug abuse were not allowed in the study.

Informed consent: An informed consent was taken from all patients after explaining all the procedures including all benefits and side effects in a simple and clear way. Also the patients had the right for withdrawal at any time.

\section{Methods}

\section{I.Preoperative phase}

History of the patient: was recorded in full details including name, age, gender, occupation, address and general medical health.
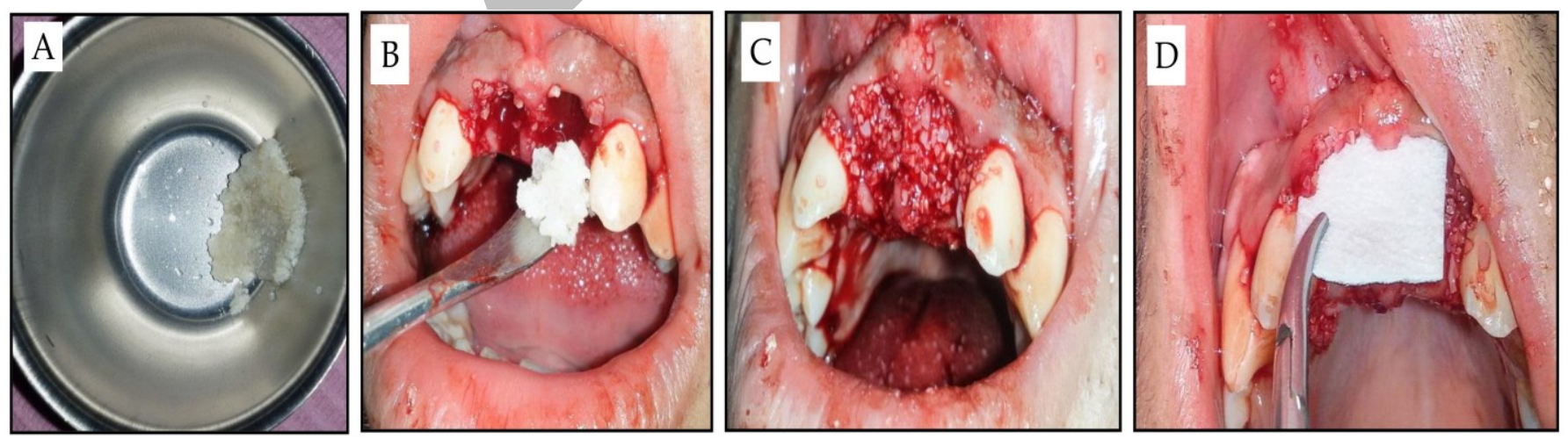

Figure (2): (A) The graft is ready to use. (b) Grafting the extraction site. (C) Extraction site after grafting. (D) Resorbable collagen membrane application. 
Resorbable collagen Membrane (Dentium collagen membrane, Korea) with slow resorbtion rate over six months period, size $15 \times 20 \mathrm{~mm}$. and $0.3 \mathrm{~mm}$ thickness, was used to cover the graft site and it was fixed in place using absorbable Coated polyglactin Suture (VICRYL® Ethicon, Inc USA) .

Releasing incision was made to allow wound edges approximation and it was closed with 000 silk Nonabsorbable sutures.

Implant placement two pieces, titanium implants (Dentium super line implants Korea.) were placed after 3 months. All implants used were standardized to be $3.6 \mathrm{~mm}$ in diameter and $12 \mathrm{~mm}$ in length for all the cases.

Elevation of a full thickness mucoperiosteal flap allow full exposer of the graft site duo to the sensitivity of bone sample collection technique and the risk of undermining the buccal plate of bone during the procedure. (Fig.3)

Dentium bone trephine with inner diameter of $2.3 \mathrm{~mm}$ and outer diameter of $3 \mathrm{~mm}$ was used to perform initial osteotomy and collect a bone sample $2.3 \mathrm{~mm}$ in diameter and $8 \mathrm{~mm}$ in length from graft site.

Drilling of the osteotomy site was made with implant motor (X CUBE V2.0 SAESHIN Korea) at 950 RPM, 32:1 gear ratio, $45 \mathrm{Ncm}$ torque and copious irrigation $75 \mathrm{ml} / \mathrm{min}$. to prepare the osteotomy site without overheating.

Final drill of $3.2 \mathrm{~mm}$. was used to reach the desired implant length of $12 \mathrm{~mm}$ and allow the $3.6 \mathrm{~mm}$ implant to achieve high primary stability from both the lateral walls and the apical part of the osteotomy.

Implants were placed with $35 \mathrm{Ncm}$ torque and 20 RPM using surgical handpiece for the apical two thirds of implant length and using $35 \mathrm{Ncm}$ torque wrench for the coronal third to reach the alveolar bone level.
Resonance frequency analysis device (OSSTELL) was used at the time of implant placement to determine the primary stability. (Fig. 4)

Immediate nonfunctional loading protocol was used to restore patient's esthetics, photonics and allow better soft tissue healing around provisional restoration to create natural emergence profile for the final restorations.

The final restorations were loaded 3 months after implant placement in the form of screw retained porcelain fused to metal crowns to facilitate the follow-up procedures

\section{III.Post-operative phase}

Post-operative instructions: cold fomentation for the first 24 hours, warm mouthwash starting from the next day, and oral hygiene recommendations.

Post-operative medication: antibiotic in the form of Amoxicillin $875 \mathrm{mg}+$ Clavulanic acid $125 \mathrm{mg}$ tablets [Augmentin 1g Glaxosmithkline (GSK)] for 7 days 2 times daily, non-steroidal anti-inflammatory drug $50 \mathrm{mg}$ tablets [Cataflam $50 \mathrm{mg}$ Novartis] for 5 days 3 times daily, and warm mouth wash chlorohexidine HCL (0.12\%) [Hexitol, Arab drug company] for one week.

Post-operative follow up: Healing was evaluated after 7 days, 45 days and 3 months for any soft tissue dehiscence, infection or inflammation. Pain was evaluated at 2 days, 7 days, and 45 days using Numeric Rating Scale (12).

Edema was evaluated at 2 days, 7 days, and 45 days by its ability to pit. The examiner fingers were pressed into dependent area for 5 seconds, and the pitting was graded on a scale of +1 to +4 (13).

Post-operative Radiographic evaluation: Three cone beam computed tomography (CBCT) and one digital periapical x-ray were used to evaluate each patient postoperatively. (Fig. 5)
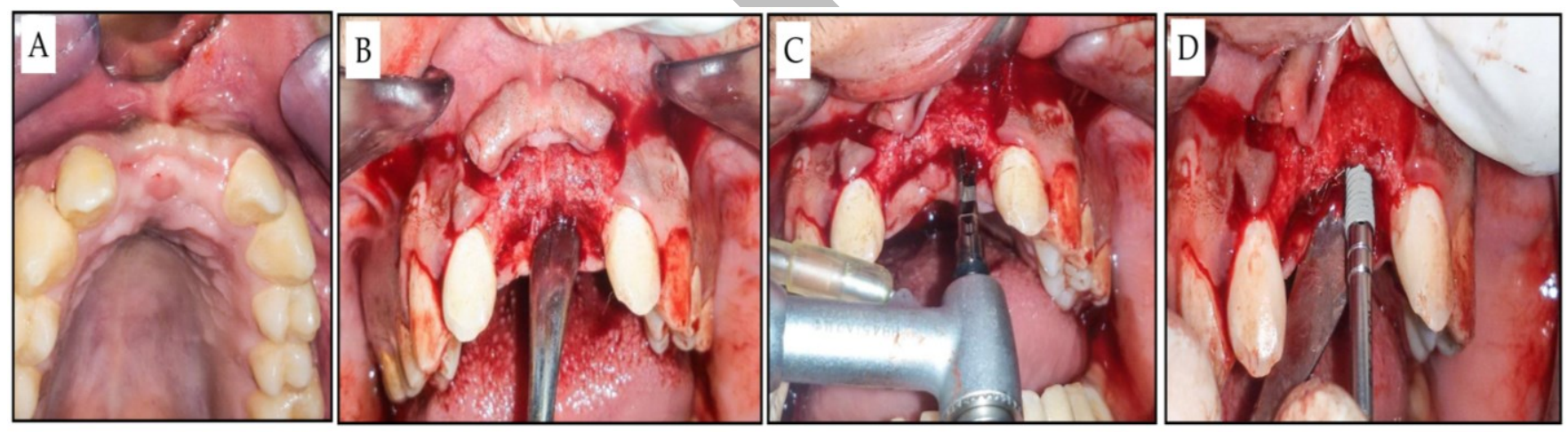

Figure (3): (A) Healing after 3 months.(B) Flap elevation showing the newly formed bone at the extraction site.(C) Using trephine bure to collect bone sample. (D) Implant placement.
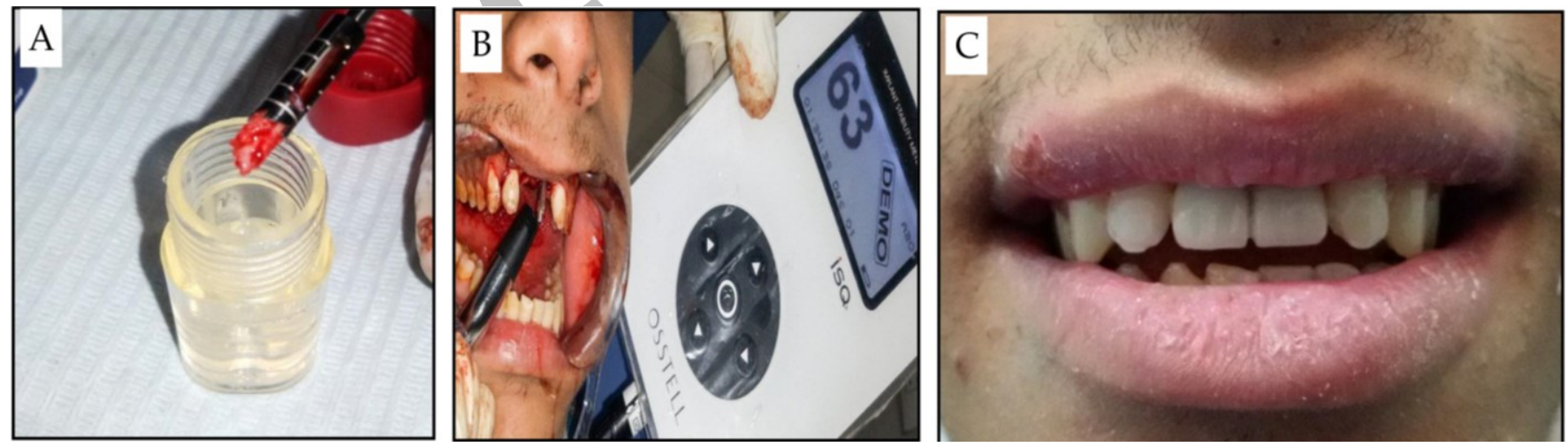

Figure (4): (A) Preserving bone specimen for histological analysis.(B) Recording osstell reading.(C) Provisional restoration. 

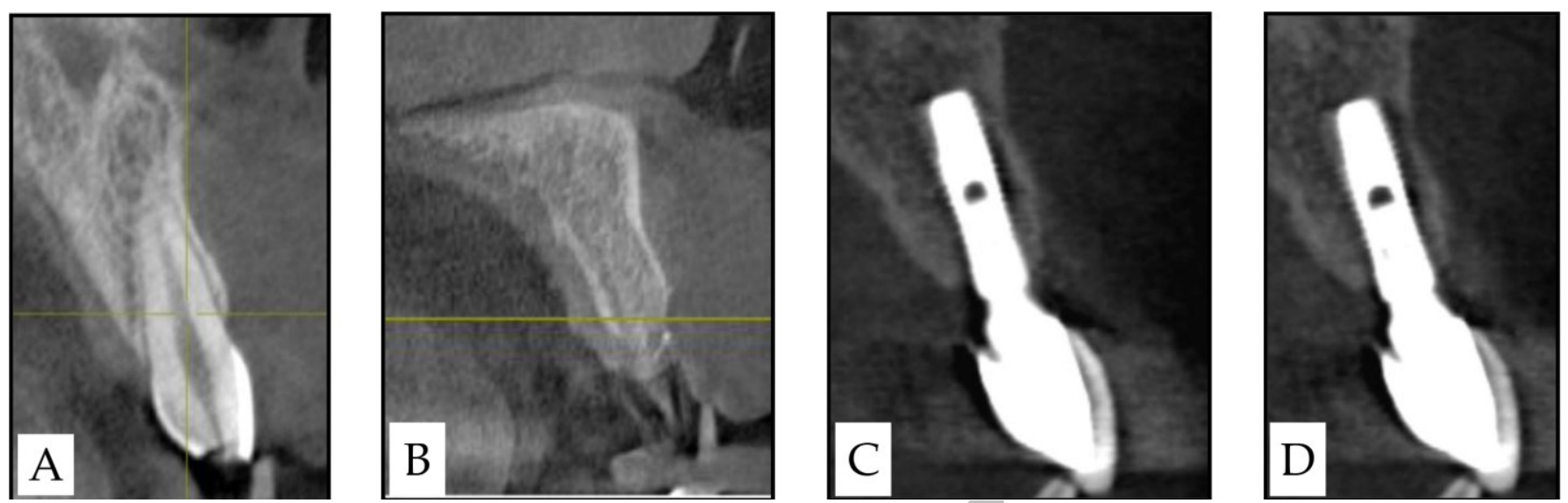

Figure (5): (A) Pre-operative CBCT axial view showing dislocation of tooth no 11 from the socket.(B) 3 months after graft placement.(C) 3 months after implant placement.(D) 6 months after implant placement.

Each patient was evaluated using (CBCT) at 3 months after graft placement to asses newly formed bone density, one digital perapical $\mathrm{x}$-ray was made immediately after implant placement to serve a reference point for marginal bone level, another (CBCT) was made at 3 and 6 months after implant placement to asses' bone density, osseointegration and marginal bone level around implants.

Bone density and osseointegration around implants were measured Using OnDemand3D software a virtual implant was placed at the grafted site and mean bone density value was calculated automatically $1 \mathrm{~mm}$ away from the implant surface.

Marginal bone level was measured at mesial and distal bone surrounding the implants were using the linear measurement system supplied OnDemand3D software.

The distance from the top of the implant platform and the first point of bone-implant contact mesially and distally were used to represent the bone defect.

Bearing in mind that we used (J.Morita veraiewpocs 3D $\mathrm{R} 100$ japan) (CBCT) machine with narrow field of view (FOV) of 4 inches, $70 \mathrm{kV}, 4 \mathrm{~mA}$; pixel size, $0.125 \mathrm{~mm}$ to produced sharp image with low radiation exposer.

Each patient received $16-20 \mu \mathrm{Sv}$ per exposer and a total of $80-100 \mu \mathrm{Sv}$ for all exposers including the preoperative
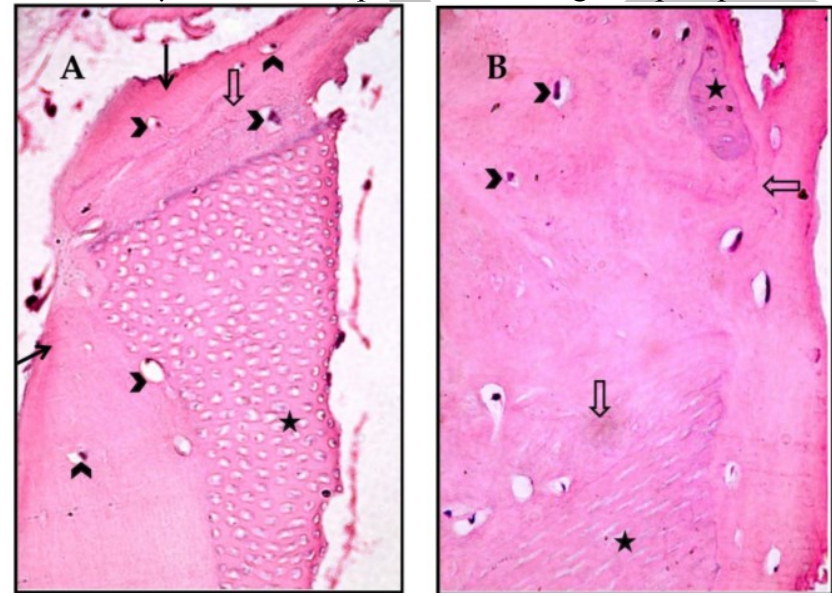

Figure (6): (A\&B) Showing: mature lamellar bone (arrows) around the AFDT graft (asterisks). Regularly distributed osteocyte lacunae (arrow heads). Note: The presence of reversal line (hollow arrows) in the newly formed bone. (C) Showing well-formed bony trabeculae (arrows) surrounding the AFDT graft (asterisk). Note: the marginal scalloping of the AFDT graft and deposition of new bone in the resorbed areas (arrow heads). Reversal lines can also see (hollow arrows). (H\&E $\times 100)$

\section{STATISTICAL ANALYSIS}

Data were fed to the computer and analyzed using IBM SPSS software package version 20.0. Quantitative data were described using range (minimum and maximum), mean, examination which is very low in comparison to the annual minimum radiation dose for the general public $1 \mathrm{mSv} / \mathrm{y}$ $(1 \mathrm{mSv}=1000 \mu \mathrm{Sv})(14,15)$

Also all the patient used lead collar for thyroid protection during all exposers and all the exposers were performed over a period of 9 months including pre-operative radiographic examination.

Implant clinical evaluation: assess Presence of pain, gingival condition around the implant using Modified sulcus bleeding index (MSBI) (16).

Final prosthesis was placed 3 months after implant placment, peri-implant probing was measured at the first, 3rd and 6th months of using plastic probe (17).

Implant stability was assessed by OSSTELL at the time of implant placement, 3 and 6 months after the implant placement. Values were measured twice in buccal and palatal directions.

\section{Histological evaluation}

Bone samples of $2.3 \mathrm{~mm}$ diameter and $8 \mathrm{~mm}$ length were acquired from the graft site by bone trephine with inner diameter of $2.3 \mathrm{~mm}$ and outer diameter of $3 \mathrm{~mm}$ trephine bur during implant placement.

Decalcified tissue sections were prepared using routine procedures and stained with hematoxylin-eosin (H\&E) and examined for quality of bone formed at the graft site. (Fig.6)

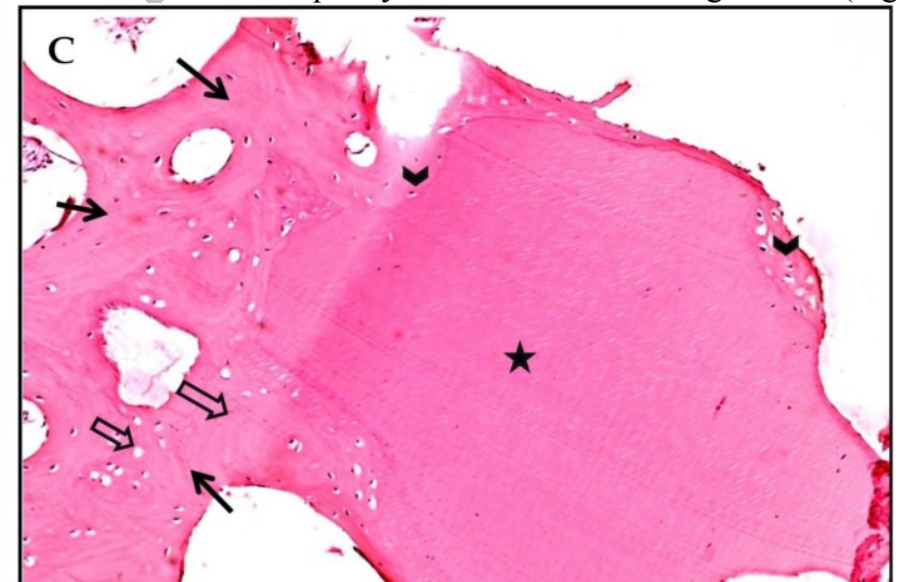

standard deviation and median. Significance of the obtained results was judged at the $5 \%$ level.

The used tests were 


\section{1- Paired t-test}

For normally quantitative variables, to compare between two periods.

\section{2- ANOVA with repeated measures}

For normally quantitative variables, to compare between more than two periods or stages, and Post Hoc test (LSD) for pairwise comparisons.

\section{RESULTS}

The present study was conducted on 10 patients 4 females and 6 males indicated for extraction of maxillary anterior or premolar teeth and implant placement, total of 4 central incisors, 2 lateral incisors, 3 canines and one maxillary first premolar were used in the study

Mean patient's age was 34.2 years. 10 implants were placed with $12 \mathrm{~mm}$ length and $3.6 \mathrm{~mm}$ diameter in the grafted sockets.

Immediate nonfunctional loading was achieved in all cases except one patient which was scheduled for tonsillectomy one week after implant placement and after consulting with his ENT surgeon we decided to postpone implant loading one week after the surgery to avoid any trauma during intubation and manipulation.

\section{Clinical evaluation}

\section{Pain tenderness, infection and/or swelling}

After surgery, $80 \%$ of the patients experienced mild pain while $20 \%$ of the patients experienced moderate pain at the surgical site and disappeared completely after the $2^{\text {nd }}$ day to $3^{\text {rd }}$ day. $80 \%$ of the patients experienced mild edema while $20 \%$ experienced moderate edema which also disappeared completely after five days.

All patients continued the follow up period without signs of infection, or inflammation.

\section{Dental implants clinical evaluation}

No signs of gingival inflammation were observed in all patients all over the evaluation period around dental implants. (i.e. modified gingival index score was score was 0 ).

Probing depth was decreasing through period of six months. The mean probing depth scores were $2.55 \mathrm{~mm} \pm 0.44$ for the first month $(\mathrm{p}<0.001), 2.05 \mathrm{~mm} \pm 0.31$ for the third month $(\mathrm{p}<0.001)$, and for the sixth month $1.73 \mathrm{~mm} \pm 0.28$ $(\mathrm{p}<0.001)$.

Radio frequency values showed increase over course of this study from $65.3 \pm 7.68$ at time of implant placement $(p<0.001)$, to $70.7 \pm 5.183$ months after implant placement $(\mathrm{p}<0.001)$, and $75.6 \pm 4.85$ at 6 months post-operative $(\mathrm{p}<0.001)$. (Table 1$)$

The results showed $15 \%$ increase in the mean OSSTELL score at 6 months' post-operative in comparison to time of implant placement.

\section{Radiographic evaluation}

\section{Evaluation of bone density and osseointegration:}

The HU values obtained from CBCT for the 10 patients showed increase in mean bone density over the course of this study from $424.24 \mathrm{HU} \pm 161.73$ pre-operatively $(\mathrm{p}<0.001)$, to $511.44 \mathrm{HU} \pm 129.18$ at three months after grafting the extraction site $(\mathrm{p}<0.001), 547.23 \mathrm{HU} \pm 122.11$ three months after implant placement $(\mathrm{p}=0.004)$, and 591.46 HU \pm 108.81 six months after implant placement $(\mathrm{p}<0.001)$.

Results showed 39\% increase in mean bone density at 6 months after implant placement when compared to preoperative values. (Table 2)

Radiographic examination showed that all implants were fully osseoitegrated with no signs of bone resorbtion or preimplantitis.
Table (1): Comparison between different time points according to osstell readings $(\mathrm{n}=10)$.

\begin{tabular}{|c|c|c|c|}
\hline Case No. & $\begin{array}{c}\text { Time of } \\
\text { implant } \\
\text { placement }\end{array}$ & $\begin{array}{l}\text { After } 3 \\
\text { months }\end{array}$ & $\begin{array}{l}\text { After } 6 \\
\text { months }\end{array}$ \\
\hline 1 & 73 & 75 & 77 \\
\hline 2 & 57 & 69 & 74 \\
\hline 3 & 71 & 73 & 80 \\
\hline 4 & 56 & 67 & 73 \\
\hline 5 & 61 & 69 & 70 \\
\hline 6 & 62 & 64 & 69 \\
\hline 7 & 63 & 63 & 71 \\
\hline 8 & 59 & 72 & 79 \\
\hline 9 & 75 & 77 & 83 \\
\hline 10 & 76 & 78 & 80 \\
\hline $\begin{array}{c}\text { Min. - } \\
\text { Max }\end{array}$ & $57-76$ & $63-78$ & $70-83$ \\
\hline $\begin{array}{c}\text { Mean } \\
\text { SD }\end{array}$ & $65.3 \pm 7.68$ & $70.7 \pm 5.18$ & $75.6 \pm 4.85$ \\
\hline Median & 62.5 & 70.5 & 75.5 \\
\hline $\mathbf{P}$ & $0.001^{*}$ & $0.001^{*}$ & $0.001^{*}$ \\
\hline
\end{tabular}

Table (2): Evaluation of bone density.

\begin{tabular}{|c|c|c|c|c||}
\hline Case No. & pre -op. & $\begin{array}{c}\text { After 3 } \\
\text { months } \\
\text { of graft }\end{array}$ & $\begin{array}{c}\text { After 3 } \\
\text { months of } \\
\text { implant } \\
\text { placement }\end{array}$ & $\begin{array}{c}\text { After 6 } \\
\text { months of } \\
\text { implant } \\
\text { placement }\end{array}$ \\
\hline $\mathbf{1}$ & 695.96 & 756.3 & 772.99 & 780.2 \\
$\mathbf{2}$ & 573.26 & 649.35 & 678.89 & 688.12 \\
$\mathbf{3}$ & 545.61 & 578.91 & 580.08 & 590 \\
$\mathbf{4}$ & 356.49 & 438.93 & 452.71 & 480.4 \\
$\mathbf{5}$ & 449.82 & 523.38 & 618.58 & 630.5 \\
$\mathbf{6}$ & 452.61 & 488.55 & 553.64 & 567.3 \\
$\mathbf{7}$ & 173.13 & 341.33 & 428.7 & 530.4 \\
\hline $\mathbf{8}$ & 177.4 & 343.89 & 371.06 & 390.2 \\
$\mathbf{9}$ & 506.99 & 594 & 615.83 & 620.23 \\
$\mathbf{1 0}$ & 429.07 & 516.34 & 523.54 & 637.25 \\
\hline Min. & $173.13-$ & $341.33-$ & $371.06-$ & $390.2-$ \\
Max & 695.96 & 756.30 & 772.99 & 780.2 \\
Mean \pm & $424.24 \pm$ & $511.44 \pm$ & $547.23 \pm$ & 591.46 \\
$\mathbf{S D}$ & 161.73 & 129.18 & 122.11 & \pm 108.81 \\
\hline $\mathbf{P}$ & 452.61 & 523.38 & 580.08 & 605.11 \\
\hline & $<0.001^{*}$ & $<0.001^{*}$ & $=0.004^{*}$ & $<0.001^{*}$ \\
\hline
\end{tabular}

Sig. bet. different time points were done using Post Hoc Test (LSD) for ANOVA with repeated measures

$\mathrm{p}_{1}$ : $\mathrm{p}$ value for comparing between preoperative and after 3 months of graft

$\mathrm{p}_{2}$ : $\mathrm{p}$ value for comparing between preoperative and after 3 month of imp.

$\mathrm{p}_{3}$ : $\mathrm{p}$ value for comparing between after 3 months of graft and imp.

*: Statistically significant at $\mathrm{p} \leq 0.05$

\section{Marginal bone height}

Marginal bone level around the implants showed minimal resorption rate through the cores of this study starting from $0 \mathrm{~mm} \pm 0$ immediately after implant to reach $0.19 \mathrm{~mm} \pm 0.06$ three months after implant placement $(\mathrm{p}<0.001)$, and 0.45 $\mathrm{mm} \pm 0.14$ at six months of implant placement $(\mathrm{p}<0.001)$. In comparison with bone level at the time of implant 
placement results show that the mean bone loss around implants in six months was $0.45 \mathrm{~mm} \pm 0.14$. (Table 3)

Table (3): Evaluation of marginal bone height.

\begin{tabular}{|c|c|c|c|}
\hline Case No. & $\begin{array}{c}\text { Post- } \\
\text { operative }\end{array}$ & $\begin{array}{c}\text { After 3 } \\
\text { months }\end{array}$ & After 6 months \\
\hline $\mathbf{1}$ & 0 & 0.2 & 0.5 \\
\hline $\mathbf{3}$ & 0 & 0.12 & 0.3 \\
\hline $\mathbf{4}$ & 0 & 0.13 & 0.3 \\
\hline $\mathbf{5}$ & 0 & 0.17 & 0.3 \\
\hline $\mathbf{6}$ & 0 & 0.2 & 0.5 \\
\hline $\mathbf{7}$ & 0 & 0.2 & 0.7 \\
\hline $\mathbf{8}$ & 0 & 0.18 & 0.5 \\
\hline $\mathbf{9}$ & 0 & 0.33 & 0.3 \\
\hline $\mathbf{1 0}$ & 0 & 0.20 & 0.5 \\
\hline Min. - Max & $0.0-0.0$ & $0.12-0.33$ & $0.30-0.70$ \\
\hline Mean \pm SD & $0.0-0.0$ & $0.19 \pm 0.06$ & $0.45 \pm 0.14$ \\
\hline Median & 0 & 0.20 & 0.50 \\
\hline P & & $<0.001^{*}$ & $<0.001^{*}$ \\
\hline
\end{tabular}

$\mathrm{p}$ value for paired t-test for comparing between im post-operative after 3 and 6 months with each other periods and mean bone loss

*: Statistically significant at $\mathrm{p} \leq 0.05$

\section{Histological evaluation}

Light microscopic examination of the bone specimens taken at the time of implant insertion revealed the osteoconductive property of autogenous fresh demineralized tooth (A.F.D.T) graft. (Fig.6)

Mature lamellar bone formation was detected surrounding the graft particles which contained regularly distributed osteocyte lacunae.

Remodeling of the newly formed bone was also evident by the presence of reversal lines between the bone lamellae.

Biodegradation of (A.F.D.T) was evident by odontoclasts cells presence on the outer surface of the (A.F.D.T) graft occupying Howship's lacunae.

The resorbed areas of the graft were replaced by the newly formed bone. The bone exhibited well developed bone trabeculae with osteocyte lacunae containing viable nuclei which occupy most of the lacunae.

Osteoinductive property of (A.F.D.T) was demonstrated by a continuous layer of active asteoblast cells seen lining the outer surface of the bone trabeculae.

Highly vascularized bone marrow tissue was detected, and other specimens showed compact bone formation which consists of concentric layers of bone lamellae surrounding centrally located Haversian canals.

\section{DISCUSSION}

The resorption of the residual alveolar bone in the vicinity of extraction sockets occurs mainly during the initial period after tooth extraction. In cases where the teeth are infected with periodontal diseases, the alveolar ridge shows more severe resorption, which may cause esthetic problems in the anterior teeth (18).

Overall results demonstrated good tissue acceptance and biocompatibility with minimal post-operative pain and edema also autogenous tooth graft was able to provide high primary stability during implant placement with mean osstell score of 65.3 at time of implant placement to increase by $15 \%$ over six months' post-operative.
Radiographical evaluation revealed progressive increase in bone density by $39 \%$ in comparison to preoperative measurements over period of 6 months also it was able to fully osseointegrate with dental implants with $100 \%$ success with minimal marginal bone loss of $0.45 \mathrm{~mm} \pm 0.14$ over period of six months.

The decision to use Immediate nonfunctional loading protocol was guided by high osstell score and implant incretion torque of $35 \mathrm{Ncm}$ during implant placement.

The good tissue acceptance and absence of severe adverse effects can be explained by two factors. First, both autogenous fresh demineralized tooth (AFDT) graft and autogenous bone are derived from the same embryonic origin which is neural crest cells so it is unlikely for the autoimmune system to produce antibodies against its own dentin (5). Secondly, the process of mechanical preparation, grinding, defatting, demineralization and sterilization leads to removal of all old restorations, pulp, cementum and bacteria so it reduces the activity of localized defense cells and minimizes the release of inflammatory and pain mediators.

Newly formed bone around dental implants and autogenous fresh demineralized tooth (AFDT) particles was able to produce direct structural and functional connection with the surface of a load-bearing dental implant indicating successful osseointegration.

The subsequent increase of osstell score from zero point [65.3] to six months [75.6] in the present study by $! 5 \%$ matches the time frames of the bone formation and maturation around the dental implants as described by Eyckmans et al (19).

According to Eyckmans et al (19), one bone remodeling cycle (activation-resorption-formation) takes about four months in humans. Initial bone resorption and formation occurs during the first month and maturation requires another four to six months.

Modified gingival index score was score was 0 as no signs of gingival inflammation were observed in all patients all over the evaluation period indicating good oral hygiene.

In contrast to natural teeth, for which average periodontal probing depth has been reported, the physiologic depth of the peri-implant sulcus of successfully osseointegrated implants has been a matter of debate (20).

The differences with respect to soft tissue composition, organization, and attachment between the gingiva and the root surface on the one hand and between the peri-implant mucosa and the implant surface on the other hand make the conditions for probing depth measurements around teeth and implants not fully comparable (21-22).

One potential explanation influencing the differences in probe penetration is that most collagen fibers in the supracrestal connective tissue compartment have been demonstrated to run mostly in a parallel direction to the implant axis (23).

In this study peri-implant probing depth improved significantly over the healing period as it started with a mean value of $2.55 \mathrm{~mm}$. at the first month after implant loading and decreased to a mean value of $2.05 \mathrm{~mm}$ on the third month of implant loading to finally reach $1.73 \mathrm{~mm}$. six months of implant loading.

This reduction of peri-implant probing depth indicates improvement of the collagen fibers arrangement and density around dental implants preventing loss of osseointegration and peri-implantitis. 
The generally accepted guidelines for implant-induced bone loss since the late $1980 \mathrm{~s}$ are less than $1.5 \mathrm{~mm}$ for the first year after implant loading and less than $0.2 \mathrm{~mm}$ for each additional year. However, other studies have suggested that these guidelines may be too lax, especially for young implant patients (24).

Significant variability in marginal bone loss following dental implants has been reported. There are studies describing a mean crestal bone loss of $0.6 \mathrm{~mm}$ for the first year and $0.2 \mathrm{~mm}$ for the following years up to 36 months after implant loading (25).

Mean annual losses of $0.03-0.05 \mathrm{~mm}$ have also been reported, and some studies have reported no change or even gains in bone level for individual implants (26).

Implant surface roughness has been shown to balance bone apposition and facilitate remodeling at the boneimplant interface, thereby minimizing marginal bone loss (27).

In our study, the mean bone loss was $0.19 \mathrm{~mm}$ three months after implant loading and $0.45 \mathrm{~mm}$ six months after implant loading about half of that suggested by Albrektsson et al (28).

The minimized marginal bone loss is possibly due to the use of rough surfaced implants which increase the contact area between implant surface and newly formed bone. Also tapered implant design allow for better stress distribution at the marginal bone -implant interface (29).

Bone density at the graft site was markedly improved during the present study as mean bone density was 424.24 Hounsfield units (H.U.) before grafting the extraction site. 3 months after graft placement the mean bone density was at the extraction site 511.44 H.U. and increased to reach 547.23 H.U. 6 months after graft placement.

This increase of bone density indicates effective new bone formation, mineralization, remodeling and maturation at the grafted site, also improvement of peri-implant bone architecture and mineralization which increases implant primary stability and osseointegration (30).

Histologically, Osteoconductive properties of autogenous fresh demineralized tooth (AFDT) graft were evident by mature lamellar bone formation surrounding the graft particles which contained regularly distributed osteocyte lacunae.

This is due to both autogenous bone and autogenous fresh demineralized tooth (AFDT) grafts have similar surface structures and physicochemical characteristics (31).

Osteoinductive properties of autogenous fresh demineralized tooth (AFDT) graft were demonstrated by a continuous layer of active osteoblast cells seen lining the outer surface of the bone trabeculae.Osteoinductivity of autogenous fresh demineralized tooth (AFDT) graft is due to the presence of Bone Morphogenic protein (BMP) in the demineralized dentine matrix although not the same as Bone Morphogenic protein (BMP) extracted from autogenous bone but very similar in action and effect on new bone formation (32).

Also the presence of non-collagenous proteins such as osteocalcin, osteonectin, and dentin phosphoprotein in demineralized dentine matrix plays an important role in bone formation and calcification (33).

Moreover, LIM mineralization protein 1 (LMP-1) which is an essential positive regulator of osteoblast differentiation and maturation and bone formation was expressed primarily in predentin, odontoblasts, and endothelial cells of the blood vessels of teeth (34).

Biodegradation of (A.F.D.T) was evident by odontoclasts cells presence on the outer surface of the (A.F.D.T) graft occupying Howship's lacunae, where resorbed areas of the graft were replaced by the newly formed bone.

This is due to both autogenous bone and autogenous fresh demineralized tooth (AFDT) grafts share low crystalline structure and possibly other calcium phosphate minerals $\beta$ tricalcium phosphate ( $\beta$-TCP), ACP, and OCP although not the same but very similar to minerals of human bone tissues (35).

The difference in crystalline structure and mineralization will allow the autogenous fresh demineralized tooth (AFDT) grafts to resorb in a slower rate than autogenous bone graft allowing for vascularization, new bone formation, remodeling and bone maturation at the graft site without loss of much of the grafted volume (36).

In comparison with current grinding mechanisms for tooth graft preparation we found our grinding technique to be safer than technique described by Murata et al (37). using liquid nitrogen to freeze the tooth and crushing it with mortar and pestle.

Also it is more economic than newly developed toothmill (DENTMILL®, Tokyo Iken Co., Ltd) at 12000rpm for 30 seconds as its grinding chamber and blade were made in $\mathrm{ZrO} 2$ which is more expensive to fabricate and maintain.

Furthermore, it requires cooling the tooth with saline ice cubes during grinding to prevent overheating and only able to grinned $(1 \times 1 \times 1 \mathrm{~cm} 3)$ of tooth at a time (37).

The defatting, demineralization and sterilization process were done using commercially available materials which were relatively safe to handle and prepare to the desired concentrations at a very low cost.

When compared to other available systems as smart dentine grinder by KometaBio ${ }^{\circledR}$ which use disposable grinding chamber and stock pre-packed defatting and sterilization chemicals which require refill our technique proves to be more cost effective (38).

Smart dentine grinder ${ }^{\circledR}$ combine grinding and sieving process together to save time but it produces calcified autogenous dentine graft as it lacks demineralization phase essential to expose the organic dentine matrix and growth factors to stimulate bone formation which will result in longer bone healing time $(5,38)$.

The use of Peracetic acid inhabited the bacterial growth in the autogenus fresh demineralize tooth (AFDT) graft due to the its strong oxidizing action which will oxidize the outer cell membranes of microorganisms (39).

The oxidation mechanism will denature proteins, disrupt cell wall permeability, and oxidize sulfhydral and sulfur bonds in proteins, enzymes, and other metabolites causing rapid deactivation of microorganisms (40).

In the presence of organic matter peracetic acid will inactivate gram-positive and gram-negative bacteria, fungi, and yeasts in $<5$ minutes at $200-500$ ppm (40).

\section{CONCLUSIONS}

Choosing the graft material should be dictated by the extent of defects and the procedural purposes, autogenous fresh demineralized tooth (AFDT) graft should be considered as a favorable option given its autogenous origin and favorable clinical, histological, radiographical outcomes, its ability to support and fully osseointegrate with dental implants, 
simple preparation technique and cost-effectiveness when teeth extraction is necessary.

\section{CONFLICT OF INTEREST}

The authors declare that they have no conflicts of interest

\section{REFERENCES}

1. Aloy-Prósper A, Peñarrocha-Oltra D, Peñarrocha-Diago M. Peri-implant hard and soft tissue stability in implants placed simultaneously versus delayed with intraoral block bone grafts in horizontal defects: A retrospective case series study. Int J Oral Maxillofac Implants 2016; 31: 133-41.

2. Shah NP, Katsarelis H, Pazianas M, Dhariwal DK. Periodontal Disease, Dental Implants, Extractions and Medications Related to Osteonecrosis of the Jaws. Dent Update 2015; 42: 878-80, 883-4, 887-89.

3. Leblebicioglu B, Hegde R, Yildiz VO. Immediate effects of tooth extraction on ridge integrity and dimensions. Clin Oral Investig 2015; 19: 1777-84.

4. Corbella S, Taschieri S, Samaranayake L. Implant treatment choice after extraction of a vertically fractured tooth. A proposal for a clinical classification of bony defects based on a systematic review of literature. Clin Oral Implants Res 2014; 25: 946-56.

5. Kim YK,Kim SG, Byeon JH, Lee HJ, Um IU, Lim SC, et al. Development of a novel bone grafting material using autogenous teeth. Oral Surg Oral Med Oral Pathol Oral Radiol Endod 2010; 109: 496-503.

6. Morrison SJ, White PM, Zock C, Anderson DJ. Prospective identification, isolation by flow cytometry, and in vivo selfrenewal of multipotent mammalian neural crest stem cells Cell 1999; 96: 737-49.

7. Nanci A. Ten Cate's oral histology: development, structure and function. $8^{\text {th }}$ ed. St Louis, Mo: Mosby Elsevier, 2008. pp 108-92.

8. Kim YK, Kim SG, Oh JS, Jin SC, Son JS, Kim SY, et al. Analysis of the inorganiccomponent of autogenous tooth bone graft material. J Nanosci Nanotechnol 2011; 11: 74425.

9. Kim GW, Yeo IS, Kim SG, Um IW, Kim YK. Analysis of crystalline structure of autogenous tooth bone graft material: X-Ray diffraction analysis. J Korean Assoc Oral Maxillofac Surg 2011; 37: 225-8.

10. Jeong KI, Kim SG, Kim YK. Clinical study of graft materials using autogenous teeth in maxillary sinus augmentation. Implant Dent 2011; 20: 471-5.

11. Lee JY, Kim YK, Kim SG, Lim SC. Histomorphometric study of sinus bone graft using various graft material. J Dent Rehabil Appl Sci 2011; 27: 141-7.

12. McCaffery M, Beebe A. Pain intensity instruments. National institutes of health - warren grant magnuson clinical center. Baltimore: VV: Mosby Company, 2003.

13. Kenneth M. Musculoskeletal Physical Examination: An Evidence-Based Approach. New Jersey: Elsevier Health Sciences, 2016. pp 145-50.

14. Zhou DD, Yao L, Guo KM. Cytogenetic evaluation of cataract patients occupationally exposed to ionizing radiation in northeast China. Genet Mol Res 2016; 15.

15. Zhang Q, Zhang Z, Yang J, Sun Q, Luo Y, Shan T, et al. CBCT-based 3D MRA and angiographic image fusion and MRA image navigation for neuro interventions. Medicine (Baltimore) 2016; 95: e4358.
16. Cacaci C, Cantner F, Mücke T. Clinical performance of screw-retained and cemented implant-supported zirconia single crowns: 36-month results. Clin Oral Investig 2016.

17. Aguilar-Salvatierra A, Calvo-Guirado JL, GonzálezJaranay M. Peri-implant evaluation of immediately loaded implants placed in esthetic zone in patients with diabetes mellitus type 2: a two-year study. Clin Oral Implants Res 2016; 27: 156-61.

18. Orti V, Bousquet P, Tramini P. Benefits of mineralized bone cortical allograft for immediate implant placement in extraction sites: an in vivo study in dogs. J Periodontal Implant Sci 2016; 46: 291-302.

19. Eyckmans J, Roberts SJ, Schrooten J, Luyten FP. A clinically relevant model of osteoinduction: a process requiring calcium phosphate and $\mathrm{BMP} / \mathrm{Wnt}$ signaling. $\mathrm{J}$ Cell Mol Med 2010; 14: 1845-56.

20. Magnusson I, Listgarten MA. Histological evaluation of probing depth following periodontal treatment. J Clin Periodontol 1980; 7: 26-31.

21. Schou S, Holmstrup P, Stoltze K. Ligature-induced marginal inflammation around osseointegrated implants and ankylosed teeth. Clin Oral Implants Res 1993; 4: 12-22.

22. Berglundh T, Lindhe J, Ericsson I. The soft tissue barrier at implants and teeth. Clin Oral Implants Res 1991; 2: 81-90.

23. Karthik K, Sivakumar, Sivaraj, Thangaswamy V. Evaluation of implant success: A review of past and present concepts. J Pharm Bioallied Sci 2013; 5(Suppl 1): S117-S9.

24. Buser D, Chappuis V, Kuchler U, Bornstein MM, Wittneben JG, Buser R, et al. Long-term stability of early implant placement with contour augmentation. J Dent Res 2013; 92(12 Suppl): 176S-82S.

25. Warren $\mathrm{P}$, Chaffee N, Felton DA. A retrospective radiographic analysis of bone loss following placement of $\mathrm{TiO} 2$ grit-blasted implants in the posterior maxilla and mandible. Int J Oral Maxillofac Implants 2002; 17: 399404.

26. Mericske-Stern R, Aerni D, Buser D. Long-term evaluation of non-submerged hollow cylinderimplants. Clin Oral Implants Res 2001; 12: 252-9.

27. Warren P, Chaffee N, Felton DA. A retrospective radiographic analysis of bone loss following placement of TiO2 grit-blasted implants in the posterior maxilla and mandible. Int J Oral Maxillofac Implants 2002; 17: 399404.

28. Albrektsson T, Zarb G, Worthington P. The long-term efficacy of currently used dental implants: a review and proposed criteria of success. Int J Oral Maxillofac Implants 1986; 1: 11-25.

29. Koodaryan R, Hafezeqoran A. Evaluation of Implant Collar Surfaces for Marginal Bone Loss: A Systematic Review and Meta-Analysis. Biomed Res Int 2016; 2016: 4987526.

30. Almasoud NN, Tanneru N, Marei HF. Alveolar bone density and its clinical implication in the placement of dental implants and orthodontic mini-implants. Saudi Med J 2016; 37: 684-9.

31. Kim YK, Kim SG, Yun PY. Autogenous teeth used for bone grafting: Acomparison to traditional grafting materials. Oral Surg Oral Med Oral Pathol Oral Radiol 2014; 117: e39-45.

32. Chung $\mathrm{PH}$, inventor. Tooth protein extracted from extracted tooth and method for using the same. Application No. 102004-0 051812 Korea intellectual property rights information service. Patent.

33. Morotome Y, Goseki-Sone M, Ishikawa I, Oida S. Gene expression of growth and differentiation factors-5, -6, and - 
7 in developing bovine tooth at the root forming stage. Biochem Biophys Res Commun 1998; 244: 85-90.

34. Wang X, Zhang Q, Chen Z, Zhang L. Immunohistochemical localization of LIM mineralization protein 1 in pulp-dentin complex of human teeth with normal and pathologic conditions. J Endod 2008; 34: 143-7.

35. Lee SH. Low Crystalline hydroxyl carbonate apatite. J Korean Dent Assoc 2006; 44: 524-33.

36. Lu J, Descamps M, Dejou J, Koubi G, Hardouin P, Lemaitre $\mathrm{J}$, et al. The biodegradation mechanism of calcium phosphate biomaterials in bone. J Biomed Mat Res Appl Biomater 2002; 63: 408-12.

37. Murata M, Akazawa T, Mitsugi M, Um IW, Kim KW, Kim YK. Human dentin as novel biomaterial for bone regeneration. In: Rosario Pignatello R (ed). Biomaterials-
Physics and Chemistry. $1^{\text {st ed }}$. Rijeka, Croatia: InTech, 2011. pp 127-40.

38. Binderman I, Halle G, Nardy C, Yaffe A, Sapoznikov L. A Novel Procedure to Process Extracted Teeth for Immediate Grafting of Autogenous Dentin. J Interdiscipl Med Dent Sci 2014; $2: 6$.

39. Williams L, Wilkins Block SS. Peroxygen compounds. In: Block SS (ed). Disinfection, sterilization, and preservation. Philadelphia: Lippincott Williams \& Wilkins, 2001. pp 185204.

40. Middleton AM, Chadwick MV, Gaya H. Disinfection of bronchoscopes, contaminated in vitro with Mycobacterium tuberculosis, Mycobacterium avium-intracellulare and Mycobacterium chelonae in sputum, using stabilized, buffered peracetic acid solution ('Nu-Cidex'). J Hosp Infect 1997; 37: 137-43. 